\title{
EDUCAÇÃO DO CAMPO: POLÍTICAS, PRÁTICAS PEDAGÓGICAS E PRODUÇÃO CIENTÍFICA*
}

\author{
Maria ANTÔNIA De SouZA*
}

\begin{abstract}
RESUMO: A intenção deste artigo é apresentar a educação do campo e sua inserção na agenda política educacional, nos últimos anos. Para isso, o texto estrutura-se em três partes: uma primeira que contextualiza a inserção da educação do campo na agenda política, destacando o papel da sociedade civil organizada; uma segunda em que apresenta características da prática pedagógica nas escolas localizadas nos assentamentos de reforma agrária no estado do Paraná e uma terceira em que descreve a produção acadêmica da pós-graduação em educação em relação ao tema educação e movimentos sociais do campo. A terceira parte resulta de uma pesquisa cujo objetivo é analisar o conteúdo das teses e dissertaçōes que discutiram educação e/ no Movimento dos Trabalhadores Rurais Sem-Terra (MST). Foram encontradas 170 pesquisas, realizadas nos Programas de Pós-Graduação em Educação no Brasil (1987-2007), tendo sido analisadas 110 delas.
\end{abstract}

Palavras-chave: Educação. Rural. Pesquisa. Movimentos sociais. Prática pedagógica.

\section{RuRAL EDUCATION: POLICIES, PEDAGOGICAL PRACTICES AND SCIENTIFIC WORK}

ABSTRACT: This paper aims to explore rural education and its place in the educational political agenda these last years. The text is organized in three parts: the first one explains how rural education fits into the political agenda and highlights the role of organized civil

* Artigo oriundo de pesquisa financiada pelo CNPq, modalidade Produtividade em Pesquisa.

** Doutora em Educação, professora do Programa de Pós-Graduação em Educação da Universidade Tuiuti do Paraná (UTP) e da Universidade Estadual de Ponta Grossa (UePG). Email: maria.antonia@pq.cnpq.br; masouza@uol.com.br 
society; the second one presents characteristic pedagogical practices in schools from land reform settlements in the State of Paraná; the last one describes post-graduate academic work on rural education and related social movements. It is the result of an analysis of theses and dissertations about education, especially within the Landless Workers Movement (MST). Out of the 160 different research projects from post-graduate programs in Education developed in Brazil (1987-2007), 108 have been analyzed so far.

Key words: Education. Rural. Research. Social movements. Pedagogical practice.

\section{Introdução}

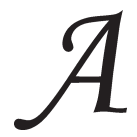

educação do campo tem conquistado lugar na agenda política nas instâncias municipal, estadual e federal nos últimos anos. Fruto das demandas dos movimentos e organizaçóes sociais dos trabalhadores rurais, a educação do campo expressa uma nova concepção quanto ao campo, o camponês ou o trabalhador rural, fortalecendo o caráter de classe nas lutas em torno da educação. Em contraponto à visão de camponês e de rural como sinônimo de arcaico e atrasado, a concepção de educação do campo valoriza os conhecimentos da prática social dos camponeses e enfatiza o campo como lugar de trabalho, moradia, lazer, sociabilidade, identidade, enfim, como lugar da construção de novas possibilidades de reprodução social e de desenvolvimento sustentável.

Os movimentos sociais, expressivamente o Movimento dos Trabalhadores Rurais Sem-Terra (MST), demandam do Estado iniciativas no âmbito da oferta de educação pública e da formação de profissionais para trabalhar nas escolas localizadas no campo. Nos dias atuais, Secretarias Municipais e Estaduais de Educação têm organizado eventos de formação continuada de professores e seminários objetivando a discussão/ construção de políticas públicas da educação do campo.

Também, as experiências do tipo parcerias, entre movimentos sociais, governos e universidades, vêm sendo desenvolvidas no Brasil objetivando a formação de professores. Aproximadamente 28 projetos educativos de nível superior para assentados da reforma agrária estão em desenvolvimento no país, sendo 20 deles cursos de Pedagogia da Terra. Em 2008, sete cursos de licenciatura em educação do campo 
estavam em fase de aprovação no Ministério de Educação. O curso de Pedagogia da Terra, por exemplo, já existiu em aproximadamente 23 estados brasileiros, tendo surgido na Universidade de Ijuí (RS), em 1998. O Programa de Educação na Reforma Agrária (PRONERA), oriundo das discussões desenvolvidas no I Encontro Nacional de Educadores da Reforma Agrária (ENERA) realizado em 1997, tem sido o principal programa destinado às parcerias de educação na reforma agrária. No PRONERA existem projetos de educação de jovens e adultos visando à alfabetização, escolarização e capacitação dos trabalhadores dos assentamentos da reforma agrária, além de projetos de formação inicial como a Pedagogia da Terra e a licenciatura em educação do campo. Existem projetos de formação continuada como a especialização lato sensu em educação do campo. Os cursos de Letras, História, Geografia e Agronomia também são desenvolvidos no contexto do PRONERA.

Temos acompanhado o debate e a inserção da educação do campo na agenda política desde 1997, quando da realização do I ENERA e mediante a participação em projetos de educação de jovens e adultos vinculados ao PRONERA. Além desse acompanhamento, realizamos no período de 2000 a 2005 pesquisas sobre a educação de jovens e adultos nas áreas de assentamentos da reforma agrária e sobre as práticas pedagógicas nas escolas localizadas nos assentamentos no estado do Paraná. No momento atual concluímos um estudo sobre o conteúdo das teses e dissertações, defendidas nos programas de pós-graduação em Educação no Brasil, que trataram de educação e/no MST no período de 1987-2007. Em função dessas pesquisas, o nosso texto segue três eixos centrais, a saber: 1) inserção da educação do campo na agenda política; 2) características da prática pedagógica nas escolas localizadas nos assentamentos da reforma agrária no estado do Paraná e 3) produção científica sobre educação do campo, em particular as pesquisas que enfatizaram educação e/no MST no período de 1987 a 2007.

Os três temas em questão permitem verificar que a educação do campo, do modo como vem sendo trabalhada pelos movimentos sociais, inaugura ao menos duas frentes no debate educacional brasileiro:

1) constrói uma noção de educação pública pautada nos interesses da sociedade civil organizada, em contraponto à educação pública estatal que historicamente marca a gestão e a prática pedagógica no Brasil. Sanfelice (2005) nos auxilia no 
entendimento do que seja a escola estatal burguesa e a escola democrática popular. Afirma que "O Estado ou o que é estatal não é público ou do interesse público, mas tende ao favorecimento do interesse privado ou aos interesses do próprio Estado, com a sua autonomia relativa" (p. 91). Segue o autor com as suas reflexões, mencionando que a educação dada pela escola pública, estatal, não pode ser considerada pública ou popular, uma vez que historicamente o estatal não é algo equivalente a público, a interesse comum. Para o autor, "a educação pública é algo a ser construído no âmbito das relaçóes contraditórias que impulsionam as sociedades e, portanto, os homens, para a superação qualitativa do modo de produção capitalista" (p. 103). Entendemos que a trajetória do MST, particularmente, na luta pela educação, expressa sinais e forças na conflituosa e contraditória relação com o Estado, na construção de uma política pública de educação do campo. $\mathrm{O}$ acúmulo de conhecimentos no movimento social fortalece o interesse público no embate com o interesse estatal. São conhecimentos que permitem questionar o modo de produção capitalista em suas contradições, bem como o lugar do Estado na estrutura capitalista; são conhecimentos e experiências educativas de mais de 20 anos que demonstram a necessidade e a possibilidade de transformar e criar processos de formação de profissionais da educação objetivando o interesse público, do povo trabalhador do campo.

2) possibilita o debate acerca da prática pedagógica nas escolas do campo, expressando as divergências políticas entre a concepção de educação rural pautada na política pública estatal e a concepção de campo pautada no debate empreendido pelos movimentos sociais de trabalhadores. Com isso, coloca professores, secretarias de educação, diretores, entre outros, em processo de indagação quanto à prática desenvolvida nas escolas do campo. Percebe-se que a educação do campo apresenta heterogeneidade no que tange à prática educativa em sala de aula e à gestão da escola, uma mostra de que a realidade, lentamente, vem sendo modificada pela prática social. A própria academia vem, aos poucos, interessando-se pela prática desenvolvida pelos movimentos sociais do campo. É 
em função disso que trazemos neste texto um pouco da realidade da produção acadêmica voltada à educação e MST, pois nos últimos anos tem sido difícil mensurar a quantidade de estudos voltados à prática do MST.

\section{Educação do campo}

A discussão que vamos empreender teve como ponto de partida a apresentação e debate sobre movimentos sociais e educação do campo em dois eventos: 1) Congresso da Associação Latino-Americana de Sociologia (UfrgS, 2005); 2) Seminário Educação na Sociedade Contemporânea: políticas educacionais e práticas educativas. Mesa-Redonda: Políticas Educacionais e Práticas Educativas, em Curitiba (UTP, 2006).

Inicialmente, é preciso mencionar a diferença primordial entre educação do campo e educação rural, tal como posta no debate acadêmico e político na atualidade. Leite (1999) nos auxilia a entender a diferença no uso das terminologias. Ele destaca o papel do Estado no desenvolvimento da extensão rural e das preocupações com o atraso educacional que permeava o meio rural no início do século xx, no Brasil. Na trajetória da educação rural, o homem do campo foi concebido como exemplo do atraso, e a política educacional se organizava em conformidade com os interesses capitalistas predominantes em cada conjuntura. Nos anos de 1960, Freire “(...) revolucionou a prática educativa, criando os métodos de educação popular, tendo por suporte filosófico-ideológico os valores e o universo sociolingüistico-cultural desses mesmos grupos" (Leite, 1999, p. 43).

Excetuando as experiências desenvolvidas por Paulo Freire; as Escolas-Família Agrícolas (EFAs) que chegaram ao Brasil na década de 1960 e as experiências das Casas Familiares Rurais (CFRs), que ocorreram em Alagoas e Pernambuco, tendo se estendido para a região Sul do Brasil, entre 1989 e 1990 (Andrade \& Di Pierro, 2004), a história da educação brasileira mostra o predomínio de uma educação que objetivava "treinar e educar" os sujeitos "rústicos" do rural.

As EFAs e as CFRs têm como sujeitos centrais os filhos dos pequenos produtores e utilizam-se da Pedagogia da Alternância, caracterizada por um projeto pedagógico que reúne atividades escolares e outras planejadas para desenvolvimento na propriedade de origem do aluno. 
Educação do campo: políticas, práticas pedagógicas e produção científica

Nos anos de 1980, com a ampliação do número de ocupações e assentamentos organizados no MST, as questôes educacionais dos camponeses e trabalhadores rurais ficaram mais visíveis. A existência de um número reduzido de escolas e o trabalho com conteúdos caracterizados pela ideologia do Brasil urbano fizeram com que o movimento social iniciasse novas experiências e produzisse documentos mostrando as necessidades e as possibilidades na construção de uma política pública de educação do campo. O movimento social questiona o paradigma da educação rural e propóe a educação do campo como um novo paradigma para orientar as políticas e práticas pedagógicas ligadas aos trabalhadores do campo. Questiona, em essência, os interesses da classe dominante expressos no paradigma da educação rural e as contradições do modo de produção capitalista.

Fernandes et al. (2004, p. 25) afirmam que a utilização da expressão campo foi adotada em função da reflexão sobre o "(...) sentido atual do trabalho camponês e das lutas sociais e culturais dos grupos que hoje tentam garantir a sobrevivência deste trabalho". A intenção explícita é resgatar o conceito de camponês. Aprofunda-se a definição de campo como

(...) lugar de vida, onde as pessoas podem morar, trabalhar, estudar com dignidade de quem tem o seu lugar, a sua identidade cultural. O campo não é só o lugar da produção agropecuária e agroindustrial, do latifúndio e da grilagem de terra. O campo é espaço e território dos camponeses e dos quilombolas (...). (Fernandes et al., 2004, p. 137)

A partir da criação do Setor de Educação (1987), responsável pela organização e sistematização de propostas e práticas pedagógicas nas escolas localizadas nos assentamentos da reforma agrária e nos acampamentos, o MST passou por um processo de fortalecimento na demanda e proposição de ações ligadas à política educacional. A educação foi conquistando lugar no interior do próprio MST, que tinha as estratégias políticas e a ocupação da terra como prioridades. As primeiras inquietaçóes originaram-se em torno das crianças dos acampamentos e dos assentamentos, evidenciando a necessidade da construção de escolas e da inserção das crianças no ambiente da educação formal. Posteriormente, as reflexões sobre práxis educativa foram ocupando espaço e gerando formulaçóes sobre o movimento social como espaço educativo (Fernandes, 1996; Gohn, 1992). 
Trabalhos de autores como Caldart (2000) demonstram as conquistas e os desafios na construção da pedagogia do MST. Arroyo (1989) salienta a existência de uma pedagogia que vai além da escola, que é organizada nos movimentos sociais, na prática social.

Existem organizações sociais, por exemplo, a Associação de Estudos, Orientação e Assistência Rural (ASSESOAR), que desenvolvem projetos alternativos para as escolas do campo, com sustentação teórica na obra de Paulo Freire. As Casas Familiares Rurais, no limite infra-estrutural e político local, propõem atendimento às necessidades escolares dos filhos dos pequenos agricultores. Organizam um projeto pedagógico com base na Pedagogia da Alternância, de forma que os filhos dos agricultores possam estabelecer articulação entre o conteúdo estudado na escola e a vivência na pequena propriedade.

A emergência da educação do campo caracteriza-se pela ausência e experiência. E a ausência de escola, de professor com formação consistente para o trabalho nas escolas localizadas nos assentamentos; ausência de técnico-agrícola; ausência de professores. Da ausência, na ação do movimento social, emerge a experiência do Instituto Técnico de Capacitação e Pesquisa da Reforma Agrária (ITERRA), da Pedagogia da Terra, da Educação de Jovens e Adultos, da Ciranda Infantil etc. Ausência e experiência desencadeiam uma prática afirmativa da educação do campo, reafirmada nos encontros estaduais, nacionais e conferências sobre educação do campo.

As discussões sobre educação do campo foram fortalecidas a partir das experiências do MST, em especial na organização dos espaços públicos, como o I Encontro Nacional de Educadores da Reforma Agrária (1997) e a I Conferência Nacional Por uma Educação Básica do Campo (1998). Na década de 1990, vários estados organizaram projetos de Educação de Jovens e Adultos, acumulando experiências para a elaboração do Programa Nacional da Educação na Reforma Agrária (1998).

A realização da I Conferência Nacional Por uma Educação Básica do Campo fortaleceu o processo de inserção da educação do campo na agenda política. A ação (experiências, encontros, documentos etc.) anterior do movimento social, na base, foi fundamental para gerar a Conferência. O encontro entre entidades internacionais (UNICEF, UNESCO) e entidades nacionais como a CNBB fortaleceram a luta pelo direito à educação e a valorização das experiências educativas do MST. 
Educação do campo: políticas, práticas pedagógicas e produção científica

São esses espaços públicos de debate e de formação política que adensam a construção de uma política, de fato, pública de educação do campo.

O lançamento do Programa Nacional da Educação na Reforma Agrária, em 1998, demonstra o fortalecimento da educação do campo na política educacional; demonstra a força dos movimentos sociais, conquistada pelo acúmulo de experiências e conhecimentos na área.

O marco da inserção da educação do campo na agenda política e na política educacional pode ser indicado a partir da LDB 9394/96, ao afirmar, em seu artigo 28 , a possibilidade de adequação curricular e metodologias apropriadas ao meio rural; flexibilizar a organização escolar, com adequação do calendário escolar.

$\mathrm{Na}$ seqüência, houve a aprovação das Diretrizes Operacionais para a Educação Básica nas Escolas do Campo, destacando que:

A educação do campo, tratada como educação rural na legislação brasileira, tem um significado que incorpora os espaços da floresta, da pecuária, das minas e da agricultura, mas os ultrapassa ao acolher em si os espaços pesqueiros, caiçaras, ribeirinhos e extrativistas. O campo, nesse sentido, mais do que um perímetro não-urbano, é um campo de possibilidades que dinamizam a ligação dos seres humanos com a própria produção das condições da existência social e com as realizações de sociedade humana. (Brasil, 2001, p. 1)

Registra-se, ainda, nas Diretrizes, a possibilidade de elaboração de

Propostas pedagógicas que valorizem, na organização do ensino, a diversidade cultural e os processos de interação e transformação do campo, a gestão democrática, o acesso do avanço científico e tecnológico e respectivas contribuiçôes para a melhoria das condiçōes de vida e a fidelidade aos princípios éticos que norteiam a convivência solidária e colaborativa nas sociedades democráticas. (Idem, ibid., p. 25)

Os seminários estaduais de educação do campo constituem outro marco da inserção desta na agenda política. Estados como Paraná criaram uma coordenação específica para as questôes da educação do campo, em 2003. Seminários estaduais acontecem em vários estados brasileiros. Acompanhando os I e II Seminários Estaduais no Paraná, foi possível verificar a presença de diretores de escolas municipais e estaduais, professores e responsáveis pelas Casas Familiares Rurais, profissionais da Associação de Estudos, Orientação e Assistência Rural, 
representantes do MST, profissionais das universidades do estado, entre outros. O Seminário vem se constituindo como um espaço público de estudos, troca de experiências e de elaboração de propostas e parcerias. Exerce uma aproximação entre os sujeitos coletivos e as instituições que se vinculam, de algum modo, à educação do campo. Com isso, informa, gera inquietações e tenta parcerias na organização das experiências educativas na educação básica, superior, de jovens e adultos e formação continuada.

Cabe destacar que esse tipo de organização - Encontros e Conferências - exige preparo em cada estado e a busca de entendimentos entre os protagonistas da educação do campo. Eles representam a sistematização das reflexões empreendidas, tanto nas instâncias governamentais, quanto nas organizações e movimentos sociais. É o espaço para formação continuada, para reflexões conjunturais, relatos de experiência e elaboração de proposição para todos os níveis de ensino, dando especificidade ao conteúdo que se quer ver discutido, quando se trata do campo como lugar de cultura e de identidades. Evidencia o encontro entre a sociedade civil organizada e o Estado, possibilitado por uma conjuntura política de abertura governamental para o diálogo com a classe trabalhadora.

Em 2004, foi criado, no Ministério de Educação, a Secretaria de Educação Continuada, Alfabetização e Diversidade (SECAD), na qual existe uma coordenação de educação do campo. Ainda, no MEC, foi organizado o Grupo Permanente de Trabalho (GPT) sobre educação do campo e foi elaborado o documento intitulado "Referências para uma política nacional de educação do campo". O Grupo anuncia dois fundamentos da educação do campo: a superação da dicotomia entre rural e urbano; relações de pertença diferenciadas e abertas para o mundo.

Os princípios da educação do campo, explícitos pelo GPT, são os seguintes: a educação do campo de qualidade é um direito dos povos do campo; a educação do campo e o respeito às organizações sociais e o conhecimento por elas produzido; a educação do Campo no campo; a educação do campo enquanto produção de cultura; a educação do campo na formação dos sujeitos; a educação do campo como formação humana para o desenvolvimento sustentável; a educação do campo e o respeito às características do campo.

Destaca-se, ainda, em 2004, a realização da II Conferência Por uma Educação Básica do Campo, que contou com aproximadamente 
Educação do campo: políticas, práticas pedagógicas e produção científica

1.100 participantes. Na declaração final da Conferência fica explícita a intenção de organizar, a partir da educação, um projeto de sociedade que seja justo, igualitário e democrático, que se contraponha ao agronegócio e que promova a realização de uma ampla reforma agrária.

Assim, é possível afirmar que a educação do campo se fortalece por meio de uma rede social, composta pelos sujeitos coletivos que trabalham com a educação do campo e que dela se aproximam. Nessa rede encontramos ONGs, universidades, secretarias estaduais e municipais de Educação, movimento sindical, movimentos e organizações sociais, centros familiares de Formação de Alternância. Ainda que o MST seja o sujeito forte na rede social, como já foi dito, ele irradia o debate da educação do campo e atrai os sujeitos que com ela trabalham, fortalecendo assim a sua própria atuação política na organização de uma proposta pedagógica que valoriza a "cultura camponesa" e que questiona as relações de classe que marcam, particularmente, a realidade do campo brasileiro. O texto de Munarim (2008) caracteriza o Movimento Nacional de Educação do Campo, que se aproxima do que denominamos rede social de sujeitos coletivos do campo.

Assim, reiteramos o nosso pensamento (Souza, 2006) de que a concepção de educação rural expressa a ideologia governamental do início do século XX e a preocupação com o ensino técnico no meio rural, considerado como lugar de atraso. Já a educação do campo expressa a ideologia e força dos movimentos sociais do campo, na busca por uma educação pública que valorize a identidade e a cultura dos povos do campo, numa perspectiva de formação humana e de desenvolvimento local sustentável.

Embora a concepção de educação do campo venha se fortalecendo nos últimos anos, vale destacar que a situação pedagógica e de infraestrutura nas escolas públicas ainda é bastante precária. Por um lado, em muitos estados as escolas passaram por um processo de nucleação - política municipal e/ou estadual de fechamento de escolas e abertura ou fortalecimento de escolas localizadas numa área central, entre bairros ou vilas rurais. Dessa forma, muitos alunos passaram a percorrer uma distância maior entre a moradia e a escola, tendo que ficar horas no transporte escolar. No que tange à prática pedagógica, a situação também é precária. Os professores nem sempre têm formação escolar superior para atuar no magistério e poucos têm acesso a bibliotecas ou materiais didáticos para desenvolver um trabalho pedagógico que vá ao 
encontro da educação do campo. São problemas - infra-estruturais e pedagógicos - que estão na pauta de reivindicações dos movimentos e organizações sociais do campo.

Contudo, é importante destacar que existem professores que buscam uma prática pedagógica diferenciada, de modo a articular os conteúdos escolares com assuntos ou experiências do cotidiano dos alunos. Embora nem sempre os professores conheçam a realidade do campo no Brasil, é necessário registrar que se esforçam para que o ensino tenha sentido sociocultural para os povos do campo. É nessa perspectiva que, na seqüência, discutimos a prática pedagógica nas escolas localizadas nos assentamentos da reforma agrária, com base em nossa investigação realizada no estado do Paraná. Uma reflexão mais detalhada sobre a prática pedagógica encontra-se em Souza (2006).

Prática pedagógica em escolas localizadas em assentamentos da reforma agrária

A prática pedagógica, entendida como uma dimensão da prática social, é gerada no estabelecimento de relação entre os conhecimentos do processo de formação inicial dos profissionais da educação e os conhecimentos adquiridos no conjunto das ações desenvolvidas no mundo da escola e da política local de educação. É desse modo que mencionamos práticas pedagógicas que se identificam com o posicionamento dos movimentos sociais quanto à educação do campo e práticas que reproduzem ideários do Brasil urbano.

A caracterização da prática pedagógica teve como ponto de partida entrevistas e questionários realizados com 60 professores que atuam nas escolas do campo, no estado do Paraná. As questōes feitas a eles versaram sobre o planejamento de ensino, orientações educacionais, seleção de conteúdos, metodologia, projetos escolares, participação dos alunos, relação aluno-professor e comunidade-professor, além da solicitação de indicação de temas que têm sido focalizados no trabalho com os anos iniciais da educação fundamental. É sabido que as escolas têm de atender a alguns requisitos municipais e estaduais, no que se refere ao desenvolvimento de projetos escolares. Por isso, os professores foram questionados sobre o assunto e solicitados a descrever quais temas fazem parte da prática pedagógica. Destacamos, a seguir, alguns resultados. 
Educação do campo: políticas, práticas pedagógicas e produção científica

\section{Planejamento pedagógico}

Os professores, predominantemente, responderam que o fazem segundo as orientaçôes da Secretaria Municipal de Educação. O planejamento é feito com base na proposta pedagógica da escola, nos Parâmetros Curriculares Nacionais e também com base em aspectos da realidade da comunidade, do assentamento. Quanto às orientações pedagógicas, destacam a presença da Secretaria Municipal da Educação e, em um dos casos, houve citação da presença de lideranças do MST, que contribuem no momento do planejamento educacional. Nos dois últimos anos, no estado do Paraná, diversos municípios têm criado a coordenação da educação do campo e realizado momentos de formação continuada que propiciam a discussão do planejamento do ensino nas escolas do campo.

A produção educacional do MST não chega às escolas. Há um conflito a ser trabalhado no que se refere à cultura, hierarquia e burocracia escolares. As secretarias municipais de educação "olham" com ressalvas para a produção do MST ou pouco conhecem dela. Os professores não tiveram contato com tais materiais nos cursos de Magistério ou de educação superior. Assim, boa parte das reflexôes produzidas pelos movimentos sociais sobre educação do campo não chega até aqueles que, de fato, fazem a realidade escolar.

\section{Proposta curricular}

Não há consenso do que seja uma proposta curricular. Alguns professores afirmaram que utilizam a proposta curricular da escola; outros a denominaram "proposta pedagógica"; já outros citaram livros que tratam interdisciplinarmente os conteúdos, fazendo referência ao nome de Paulo Freire. Um professor fez referência a uma "proposta construtivista interacionista piagetiana", enquanto outros citaram a utilização de jornais e panfletos.

\section{Conteúdos escolares}

Os professores dão relevância aos aspectos da comunidade e da realidade local na seleção dos conteúdos escolares, embora o livro didático seja o instrumento central no trato dos conteúdos. Os PCN são 
citados como proposta, embora sejam um documento que oferece indicadores para o desenvolvimento de uma educação na esfera nacional. Percebe-se a importância que a formação continuada de professores e de educadores poderia exercer para aqueles que atuam no campo, pois seria um espaço propiciador de problematização da experiência e angústias pedagógicas vividas, um espaço de trocas e de construção de novos conhecimentos educacionais e de apropriação de conteúdos escolares.

Os professores foram unânimes em afirmar que os conteúdos são elaborados a partir da "realidade" dos alunos, da comunidade, "temas essenciais para o dia-a-dia do educando". Fizeram referência a conteúdos tais como: lixo, água, limpeza, atividades econômicas, meio ambiente, família, classes sociais, direitos e deveres das comunidades, entre outros. $\mathrm{Na}$ referenciação aos temas, é possível perceber a preocupação com o sentido do conteúdo/conhecimento para a vida do aluno, embora fundamentados nas orientaçôes curriculares locais ou nacionais oficiais.

O professor da escola localizada no assentamento enfrenta o conflito entre organizar um conteúdo independente das orientaçôes oficiais do Estado ou seguir os documentos e livros de sua escolha, fazendo as relações possíveis.

\section{Metodologia de ensino}

Os professores destacam a presença de aulas expositivas, leitura, debates, trabalhos em grupos, rodas de conversas, trabalhos práticos, pesquisas, leituras partilhadas, desenhos, ilustraçóes etc. Um professor afirmou que "trabalha com a participação ativa dos educandos e intervenção do professor; o educando é construtor de conhecimentos". Os educandos são descritos pela maioria dos entrevistados como sujeitos que participam, conversam, discutem assuntos da aula, sob a intervenção do professor. Enfim, a interação social sob a perspectiva da racionalidade comunicativa parece ser uma das características metodológicas na prática nas escolas do campo.

\section{Projetos escolares}

Os professores indicam que há projetos escolares e que eles estão relacionados com a localidade: trabalho com hortas, datas comemorativas, conservação da água, plantio de árvores etc. Há ênfase na 
Educação do campo: políticas, práticas pedagógicas e produção científica

participação da comunidade, uma vez que os professores salientam a presença dos funcionários da escola e comunidade em alguns dos projetos.

Nas falas dos professores é possível identificar as seguintes características dos projetos escolares: os temas são identificados na própria comunidade, dando destaque para as datas comemorativas; história do assentamento, literatura; resgate da cultura dos alunos assentados e acampados; jogos escolares de $1^{\mathrm{a}}$ à $4^{\mathrm{a}}$ séries; visita a outros assentamentos; alimentos do campo. Os participantes são pessoas da própria comunidade, professores, funcionários da escola, alunos, lideranças, agrônomos e acampados. A dinâmica dos projetos é caracterizada pela interação da comunidade no contexto escolar, pelo estabelecimento de relaçôes com outros assentamentos e atividades em grupos, a exemplo de uma experiência que teve o objetivo de conscientizar sobre a importância dos alimentos e da produção orgânica.

Os projetos escolares são aqueles que podem ser desenvolvidos ao longo do ano, por um ou mais professores, envolvendo a comunidade. A escola do campo oferece uma infinidade de possibilidades curriculares. Numa aproximação com a realidade escolar, observando os aspectos da rotina da escola, constata-se a presença de pessoas da comunidade no ambiente escolar, além do fato de que muitos funcionários são moradores do próprio assentamento. É algo que aproxima professores que são de outras localidades das pessoas da própria localidade.

Os alunos e a comunidade assentada sentem-se à vontade para falar da vida no assentamento. Alguns evitam falar da vida no acampamento em função da perda de amigos e do enfrentamento da fome, frio, doenças, violência e discriminação social. Uma professora destacou que, ao trabalhar com o tema discriminação racial, como conteúdo da aula, um aluno disse: "nós sem-terra somos discriminados". Outro professor ressaltou que, no trabalho com adolescentes, é muito difícil discutir identidade, pois muitos deles não querem ser identificados como "sem-terra". O professor vive a heterogeneidade da expressão de idéias e sentimentos em sala de aula; eis o desafio para ele: conhecer os processos de luta pela terra no MST e em outros movimentos sociais, em outros momentos históricos, é fundamental para avançar o debate com os alunos sobre a identidade e os sentimentos de "pertença" ou de "recusa". 
Partindo dos questionamentos sobre a seleção dos conteúdos, a metodologia, a relação professor e alunos, a avaliação, a existência de projetos escolares e a relação entre escola e comunidade, foi possível caracterizar aspectos da prática pedagógica que indicam duas direções: 1) uma prática que manifesta a proximidade com os propósitos filosóficos, pedagógicos e políticos do MST. Nela, o professor retrata o trabalho com os temas que integram o cotidiano da comunidade assentada; discute a trajetória de vida dos alunos e a história do assentamento; atribui importância à participação da comunidade na escola, tenta desenvolver um trabalho participativo com os alunos. Trata-se de um professor que conhece algumas características dos povos do campo ou que procura conhecê-las em seu trabalho educativo; 2) uma prática que se caracteriza pela proximidade do professor com as orientações oficiais, sejam elas municipais ou estaduais. O conteúdo fica centralizado na indicação realizada pelas instâncias governamentais e no livro didático, que muitas vezes é o único material existente na escola. Nas duas práticas constatou-se a utilização da palavra "realidade" para ilustrar os conteúdos que são desenvolvidos em sala de aula. O discurso crítico parece estar incorporado nas práticas tradicionais, descaracterizando-as.

$\mathrm{O}$ relato dos aspectos da prática pedagógica permite visualizar que a inserção da educação do campo na agenda política é bem recente no espaço local, o município. Muitas localidades apresentam resistências quanto a movimentos sociais, particularmente o MST, em função das relações patrimonialistas na gestão da coisa pública e da força que a categoria "propriedade" exerce no mundo das relaçóes locais.

Cabe comentar que a maioria dos professores não tem vínculos orgânicos com o MST e que estes não se orientam unicamente pela política oficial na conduta da aula. Eles se esforçam para organizar um processo pedagógico em que os conteúdos escolares oficiais sejam registrados, mas que, também, os conteúdos do mundo da vida dos alunos sejam considerados. Para isso, os professores procuram conhecer as famílias e as atividades econômicas predominantes na localidade, de forma a ter elementos para o planejamento das aulas. A prática pedagógica torna-se um exercício de aprendizagem de conteúdos que não são trabalhados no momento da formação inicial do professor, como é o caso da característica do campo brasileiro, suas relações de trabalho e conflitos de classe.

Em síntese, ainda que haja avanços quanto à inserção da educação do campo na agenda política, o grande desafio está na formação de 
Educação do campo: políticas, práticas pedagógicas e produção científica

professores e nas condições infra-estruturais das escolas do campo. A educação é mais um direito social que, quando garantido, propicia a ampliação da formação humana e da dignidade da pessoa. Diante dos determinantes estruturais e conjunturais da sociedade brasileira, não será a educação que permitirá aos povos do campo continuarem no campo, mas, sem dúvida, ela é um direito humano fundamental para que eles tenham dignidade e meios de lutar pelas condições básicas de vida, no lugar em que escolheram para viver.

Estudos sobre movimentos sociais do campo e educação têm aumentado nos últimos anos, provavelmente em função da dinâmica societária, comentada anteriormente, de inserção da educação do campo na agenda política. Damasceno e Beserra (2004) demonstram o irrisório número de pesquisas sobre educação rural no Brasil, no período de 1980 a 1990. Ribeiro (2007) traz contribuições para o debate da educação do campo, ao apresentar uma série de resultados de pesquisas locais e expor o movimento contraditório que marca os conceitos de educação rural/do campo; os movimentos sociais e a educação popular. Ainda, Vendramini (2007) problematiza as pesquisas sobre movimentos sociais, educação e trabalho, desde o conceito de classe em Thompson.

Em nosso estudo, focalizamos o período de 1987 a 2007 e somente as pesquisas que trataram de educação e/no MST. São 170 trabalhos, entre teses e dissertações defendidas nos programas de pós-graduação stricto sensu em Educação no Brasil. Nos trabalhos, são perceptíveis duas vertentes teóricas principais: 1) educação formal: que agrega pesquisas que focalizaram a escola, prática do professor, propostas político-pedagógicas, educação infantil, educação física, metodologias de ensino, relação professor-aluno, formação de educadores, educação de jovens e adultos etc.; 2) educação não-formal: que agrega pesquisas que discutiram identidade "sem-terra", consciência política, trabalho e educação, enfim, que focalizam o MST como espaço educativo. Na seqüência, trazemos um panorama das pesquisas sobre educação e MST.

Produção científica: educação do campo e movimentos sociais

O objetivo central da pesquisa em foco é analisar o conteúdo das teses e dissertações que trataram de educação e/no MST. O levantamento de dados das teses e dissertações teve início no Banco de Teses da 
CAPES e prosseguiu por meio da consulta nos diversos sites das universidades que têm programas de pós-graduação em Educação. Atualmente, são 92 programas no Brasil. No momento da pesquisa havia 83 programas de pós-graduação em educação. Dos 83 programas existentes à época, encontramos teses e dissertações defendidas na área de Educação em 31 deles, sendo 125 pesquisas de mestrado e 45 de doutorado.

De posse de $50 \%$ dos trabalhos identificados, partimos para outra fase de levantamento de dados: a consulta à lista de referências de cada uma das teses e dissertações, a partir da qual foi possível identificar outras pesquisas já desenvolvidas em programas de pós-graduação em Educação. Com isso, atingimos o número de 170 pesquisas defendidas no período de 1987 a 2007.

As universidades classificadas nos primeiros seis lugares em número de pesquisas defendidas em educação são: UNICAMP, UFSC, UFRGS, UFPB, UFC e UFPR. Outras universidades que têm pesquisas defendidas na área são: UFSCAR, USP, UFF, UFG, UNB, UFBA, UFSM, UFRN, UFPEL, UNESP/Marília, UFPE, PUC/SP, UNISINOS, UEM, UFMT, UFMS, UFMA, UCDB, UEPG, UCGO, UNIUUI, PUC/RS, PUC/RIO, UFES e UTP. Mais detalhes da pesquisa estão apresentados em Souza (2007).

Embora as pesquisas estejam concentradas na grande região Centro-Sul do Brasil, em especial nos estados de São Paulo, Paraná, Santa Catarina e Rio Grande do Sul, é importante registrar a tendência no crescimento das pesquisas na regiáo Nordeste do Brasil. A concentração delas na região Centro-Sul se deve, também, à concentração dos programas de pós-graduação em Educação nessas regiōes, mas, em contrapartida, a participação efetiva do MST nessas localidades demanda aos pesquisadores estudos sobre a luta por educação e as diversas experiências de formação vinculadas ao movimento social. A dinâmica societária inquieta alguns pesquisadores que se desafiam a compreender a "história em movimento". Na região Nordeste, em função do fortalecimento de grupos de pesquisas, em especial nas UFC/Fortaleza, UFRN, UFPB, UFBA tem havido um crescimento do número de pesquisas, expressivo na UFPB, por exemplo. Outro fator que fortalece as pesquisas sobre a temática na região Nordeste tem sido a presença marcante de projetos vinculados ao PRONERA.

$\mathrm{O}$ crescimento das pesquisas ocorreu a partir do final dos anos de 1990. Na década de 1980 foram defendidas 2 pesquisas na área; 
Educação do campo: políticas, práticas pedagógicas e produção científica

na década de 1990 foram defendidas 28 e 140 foram defendidas no período de 2000 a 2007. Podemos inferir que a dinâmica societária, particularmente as parcerias, e a atuação dos movimentos sociais têm suscitado entre os pesquisadores o interesse pelo desvelamento de aspectos relacionados à educação ou outras problemáticas socioambientais, socioculturais e sociopolíticas presentes na sociedade brasileira.

A preocupação com aspectos da educação escolar e da dimensão sociopolítica dos movimentos sociais gera a diversidade de temáticas/ problemáticas presentes nas investigações. Ainda, questões que englobam fatores culturais, relacionados à sexualidade, gênero, juventude e religião marcam lugar nas pesquisas.

Os textos têm início, na maioria dos casos, com uma descrição sobre a luta pela terra e o surgimento do MST. É reconhecido que a concentração de terras e a oposição entre classes trabalhadoras e latifundiárias são fatores estruturais que geram as lutas pela sua posse.

É importante destacar que a maioria dos trabalhos de mestrado faz uma retrospectiva do MST muito semelhante, ou seja, são repetitivas no quesito "histórico". Considerando a produção acadêmica sobre este Movimento, um desafio para os novos pesquisadores é superar a dimensão da reprodução (daquilo exaustivamente já dito) da trajetória do MST e da luta pela terra no Brasil. Para isso, é fundamental que os novos pesquisadores tenham acesso às teses e dissertaçôes, para que possam fazer sínteses acerca da historicidade da luta pela terra (totalidade) e dedicar-se mais à produção de novos conhecimentos sobre o Movimento e, em específico, a educação, seja ela na sua dimensão formal ou não-formal. Com isso, não há intenção de que os trabalhos abandonem o aspecto da historicidade e contextualização necessárias ao objeto da pesquisa, mas que valorizem o desenvolvimento de sínteses ao falar da luta pela terra no Brasil.

Nos trabalhos há predomínio da abordagem qualitativa de pesquisa. É comum a apresentação de relatos da participação e vivência no assentamento ou acampamento, durante um período de tempo. As técnicas de coleta de dados têm sido caracterizadas por entrevistas, observação, análise de documentos, relatos orais, questionários, uso de fotografias, dinâmica de grupo etc.

Do ponto de vista teórico, as pesquisas têm indicado um movimento de articulação entre conceitos da Educação e da Sociologia, 


\section{Tabela 1}

Temáticas presentes nas pesquisas dos PPGED

\begin{tabular}{|c|c|}
\hline Temas presentes nas pesquisas & Total \\
\hline $\begin{array}{l}\text { Educação escolar, pedagogia do MST, curso técnico, DER, Escola Terra de Educar, } \\
\text { gestão democrática, implantação da proposta pedagógica, proposta educativa do MST. }\end{array}$ & 55 \\
\hline EJA, alfabetização, etnomatemática, PRONERA, educação e reforma agrária. & 25 \\
\hline $\begin{array}{l}\text { Dimensão socioeducativa, cooperação, autonomia, autogestão Princípio educativo } \\
\text { do trabalho cooperativo. }\end{array}$ & 11 \\
\hline Dimensão cultural no MST, mística, teatro-educação, lúdico e revolucionário. & 10 \\
\hline Práticas educativas no MST. & 10 \\
\hline Formação de educadores/ professores. & 10 \\
\hline Sujeito Sem-Terra, consciência política, identidade coletiva. & 8 \\
\hline Movimento social; movimento de luta por escola. & 7 \\
\hline Educação Infantil & 6 \\
\hline Professores/cotidiano pedagógico/organização do trabalho Pedagógico. & 6 \\
\hline Consciência política (jovens); consciência de classe. & 6 \\
\hline Currículo & 5 \\
\hline Subjetividade/mulheres; questôes de gênero. & 3 \\
\hline Educação e líderes de trabalhadores rurais (discurso). & 1 \\
\hline Religiāo e Educação & 1 \\
\hline Extensão rural & 1 \\
\hline Sexualidade e jovens & 1 \\
\hline José Martí/ideário político pedagógico. & 1 \\
\hline Comunicação e linguagem de jovens e adultos. & 1 \\
\hline Trabalhador com (d) eficiência física no MST. & 1 \\
\hline MST na telenovela & 1 \\
\hline Total & 170 \\
\hline
\end{tabular}

Fonte: leitura de 110 pesquisas na íntegra e leitura de 60 resumos.

Educ. Soc., Campinas, vol. 29, n. 105, p. 1089-1111, set./dez. 2008

Disponível em <http://www.cedes.unicamp.br> 
Educação do campo: políticas, práticas pedagógicas e produção científica

especialmente. Da Sociologia são lembrados recorrentemente autores, como Ilse Scherer-Warren, José de Souza Martins e Maria da Glória Gohn. Da Educação, os autores mais citados são Paulo Freire, Miguel Arroyo, Roseli Salete Caldart, Moacir Gadotti, Gaudêncio Frigotto, entre outros. Da discussão sobre classes sociais, autores como Karl Marx, Antonio Gramsci e Eric Hobsbawn são citados de forma significativa. Para fundamentar o debate sobre o MST, os pesquisadores fazem uso das obras de autoria de João Pedro Stédile e Bernardo Mançano Fernandes, basicamente. No que tange o debate da realidade no assentamento de reforma agrária, são citadas as pesquisas de Sérgio Leite e Leonilde Medeiros.

Das teses e dissertações mais referenciadas nas pesquisas, destacase a de Célia Regina Vendramini (1992). Quanto ao conceito de movimentos sociais, as autoras Maria da Glória Gohn e Ilse Scherer-Warren são as mais referenciadas. Observa-se a constituição de um quadro de referenciais teóricos que não possui uma base exclusiva de autores de uma matriz teórica. $\mathrm{O}$ que se percebe nos textos é a utilização de várias obras - independente da filiação teórica - na compreensão da educação no movimento social. As teses de Ilma Machado (2003) e Célia Regina Vendramini (1998) constituem dois exemplares da perspectiva marxista na compreensão da organização do trabalho pedagógico e da consciência de classe, respectivamente.

No momento atual, estão surgindo trabalhos que discutem a relação entre o MST e os governos, em função principalmente da criação do Programa Nacional da Educação na Reforma Agrária, no ano de 1998, cujos projetos de educação de jovens e adultos começaram a ser analisados a partir dos anos de 1999. Também, com os avanços do debate sobre a educação do campo, existem trabalhos focalizando as propostas do MST, a articulação nacional em torno da educação do campo, as ações nos estados etc. Ou seja, mais uma demonstração de que a dinâmica societária desperta, entre os pesquisadores, o interesse por determinadas problemáticas "em movimento" no momento histórico atual.

Esperamos, enfim, que a caracterização da educação do campo, apresentada ao longo deste texto, possa motivar os leitores à reflexão sobre a educação na sociedade contemporânea para fora dos limites do espaço urbano. Afinal, o Brasil caracteriza-se por um grande número de municípios (com pequenos núcleos urbanos) nos quais as relações sociais e econômicas fundam-se nos valores da vida e cultura camponesas. Também, que possa motivar a reflexão sobre o papel da sociedade civil 
organizada na conquista de espaços na agenda política e na efetivação de uma educação pública, de fato, oriunda dos anseios dos povos do campo. $\mathrm{Na}$ organização das políticas e práticas pedagógicas há uma prática educativa que se constrói na participação sociopolítica.

Por fim, cabe dizer que os desafios da pesquisa sobre a educação do campo são: aprofundar a compreensão de quais conhecimentos científicos os professores dominam e quais são necessários para a efetivação de uma prática pedagógica transformadora. A construção da educação do campo vem sendo marcada por uma prática social que indaga a educação pública estatal e que demanda/fortalece a educação pública proveniente das reflexões dos povos do campo. Analisar a articulação que tem havido entre a sociedade civil organizada e o Estado contribuirá na compreensão da trajetória da educação do campo, como uma nova concepção de educação e de campo no Brasil, fundada nas relações de classe.

Recebido em julho de 2007 e aprovado em dezembro de 2007.

\section{Referências}

ANDRADE, M.R.; DI PIERRO, M.C. Programa Nacional de Educação na Reforma Agrária em Perspectiva: dados básicos para uma avaliação. São Paulo: Ação Educativa, 2004.

ARROYO, M.G. A escola e o movimento social: relativizando a escola. Revista da ANDE, São Paulo, n. 12, 1989.

ARROYO, M.G.; CALDART, R.S.; MOLINA, M.C. (Org.). Por uma educação do campo. Petrópolis: Vozes, 2004.

BRASIL. Ministério da Educação. Conselho Nacional de Educação. Diretrizes operacionais para a Educação Básica nas Escolas do Campo. Brasília, DF, 2001.

BRASIL. Ministério da Educação. Grupo de Trabalho de Educação do Campo. Referências para uma política nacional de educação do campo. Caderno de Subsidios, Brasília, DF, 2003.

CALDART, R.S. Pedagogia do Movimento Sem-Terra. Petrópolis: Vozes, 2000. 
Educação do campo: políticas, práticas pedagógicas e produção científica

DAMASCENO, M.N.; BESERRA, B. Estudos sobre educação rural no Brasil: estado da arte e perspectivas. Educação \& Pesquisa, São Paulo, v. 30, n.1, p. 73-89, jan./abr. 2004.

FERNANDES, B.M. MST: formação e territorialização. São Paulo: Hucitec, 1996.

FERNANDES, B.M. Diretrizes de uma caminhada. In: Arroyo, M.G; Caldart, R.S.; Molina, M.C. Por uma educação do campo. Petrópolis: Vozes, 2004. p. 133-145.

FERNANDES, B.M.; CERIOLI, P.; CALDART, R.S. Primeira Conferência Nacional por uma Educação Básica do Campo. In: Arroyo, M.G; Caldart, R.S.; Molina, M.C. Por uma educação do campo. Petrópolis: Vozes, 2004. p. 19-62.

GOHN, M.G. Movimentos sociais e educação. São Paulo: Cortez, 1992.

LEITE, S.C. Escola rural: urbanização e políticas educacionais. São Paulo: Cortez, 1999.

MACHADO, I.F. A organização do trabalho pedagógico em uma escola do MST e a perspectiva da formação omnilateral. 2003. 325f. Tese (Doutorado) - Faculdade de Educação, Universidade Estadual de Campinas, Campinas.

MOLINA, M.C. (Org.). Educação do campo e pesquisa: questões para reflexão. Brasília, DF: Ministério do Desenvolvimento Agrário, 2006.

MUNARIM, A. Movimento nacional de educação do campo: uma trajetória em construção. 17f. Trabalho apresentado no GT 3: Movimentos sociais e educação, 31 ${ }^{\text {a }}$ Reunião Anual da ANPEd, Caxambu, MG, 2008. Disponível em: <http://www.anped.org.br>. Acesso em: 6 nov. 2008.

SANFELICE, J.L. Da escola estatal burguesa à escola democrática e popular: considerações historiográficas. In: Lombardi, J.C.; SAVIANI, D.; NASCimento, M.I.M. (Org.). A escola pública no Brasil: história e historiografia. Campinas: Autores Associados; HISTEDBR, 2005. p. 89-105.

SOUZA, M.A. Educação do campo: propostas e práticas pedagógicas do MST. Petrópolis: Vozes, 2006. 
SOUZA, M.A. A pesquisa sobre educação e o Movimento dos Trabalhadores Rurais Sem-Terra (MST) nos Programas de Pós-Graduação em Educação. Revista Brasileira de Educação, Rio de Janeiro, v. 12, n. 36, p. 443-461, set./dez. 2007.

RIBEIRO, M. Educação do campo: a emergência de contradiçôes. In: Gracindo, R.V. (Org.). Educação como exercício de diversidade: estudos em campos de desigualdades sócio-educacionais. Brasília, DF: Líber Livro, 2007. p. 153-170.

VENDRAMINI, C.R. Ocupar, resistir e produzir - MST: uma proposta pedagógica. 1992. 184f. Dissertação (Mestrado em Educação), Universidade Federal de São Carlos, São Carlos.

VENDRAMINI, C.R. Pesquisa e movimentos sociais. Educação \& Sociedade, Campinas, v. 28, n. 101, p. 1395-1409, set./dez. 2007. 